Journal of Patient-Centered

Volume 1

Issue 3 - Cardio-Oncology

Article 2

8-13-2014

\title{
Clinical Outcomes of Unprotected Left Main Coronary Artery Stenting in Nonsurgical Patients: A Single-Center Experience
}

John-Paul Pham

Abdelazim Hashim

Naoyo Mori

Mohamed Taha

Mohamed Djelmami-Hani

Joaquin Solis

Suhail Allaqaband

Tanvir Bajwa

Anjan Gupta

Follow this and additional works at: https://aah.org/jpcrr

Part of the Cardiology Commons, and the Cardiovascular Diseases Commons

\section{Recommended Citation}

Pham J, Hashim A, Mori N, Taha M, Djelmami-Hani M, Solis J, Allaqaband S, Bajwa T, Gupta A. Clinical outcomes of unprotected left main coronary artery stenting in nonsurgical patients: a single-center experience. J Patient Cent Res Rev. 2014;1:114-120. doi: 10.17294/2330-0698.1024

Published quarterly by Midwest-based health system Advocate Aurora Health and indexed in PubMed Central, the Journal of Patient-Centered Research and Reviews (JPCRR) is an open access, peer-reviewed medical journal focused on disseminating scholarly works devoted to improving patient-centered care practices, health outcomes, and the patient experience. 


\title{
Clinical Outcomes of Unprotected Left Main Coronary Artery Stenting in Nonsurgical Patients: A Single-Center Experience
}

\author{
John-Paul Pham, MD, ${ }^{1}$ Abdelazim Hashim, MD, ${ }^{1}$ Naoyo Mori, PhD,${ }^{2}$ Mohamed Taha, MD, ${ }^{1}$ Mohamed \\ Djelmami-Hani, MD, ${ }^{1}$ Joaquin Solis, MD, ${ }^{1}$ Suhail Allaqaband, MD,${ }^{1}$ Tanvir Bajwa, MD,${ }^{1}$ Anjan Gupta, MD ${ }^{1}$ \\ ${ }^{1}$ Aurora Cardiovascular Services, Aurora Sinai/Aurora St. Luke's Medical Centers, University of Wisconsin School of \\ Medicine and Public Health, Milwaukee, WI \\ ${ }^{2}$ Center for Urban Population Health, University of Wisconsin-Milwaukee, Milwaukee, WI
}

\begin{abstract}
Purpose: Coronary artery bypass graft is the standard treatment for unprotected left main disease; however, some patients are poor surgical candidates due to comorbidities. We assessed the safety and clinical outcome of elective, unprotected left main coronary artery stenting in nonsurgical patients.
\end{abstract}

Methods: Between October 2004 and June 2006, 50 consecutive patients underwent elective, unprotected left main coronary artery stenting at our institution. Patients were followed for a median of 16 and 96 months and clinical outcomes monitored.

Results: Median logistic euroSCORE was 28.6 (interquartile range: 14.6-43.4). Median baseline left ventricular ejection fraction (LVEF) was 50\%. Procedural success rate was $100 \%$. The rates of cerebrovascular accident, myocardial infarction, target vessel revascularization and cardiovascular death were $2 \%, 4 \%, 4 \%$ and $2 \%$, respectively, at 30 days, $2 \%, 6 \%, 6 \%$ and $2 \%$ at 16 months, and $2 \%, 6 \%, 12 \%$ and $4 \%$ at 96 months. Major adverse cardiac and cerebrovascular event rate was $12 \%$ at 30 days, $16 \%$ at 16 months and $24 \%$ at 96 months. Median LVEF at 16 months was 55\%, significantly improved from baseline $(\mathrm{P}<0.001)$.

Conclusion: In nonsurgical patients with left main disease, stenting of the unprotected left main coronary artery is safe, with acceptable rates of major adverse cardiac and cerebrovascular event up to 96 months poststenting. (J Patient-Centered Res Rev. 2014;1:114-120.)

\section{Keywords}

left main coronary artery, stenting, percutaneous coronary intervention, percutaneous revascularization, coronary artery disease

Correspondence: Anjan Gupta, MD, Aurora Cardiovascular Services, 2801 W. Kinnickinnic River Parkway, \#840, Milwaukee, WI, 53215, Phone: 414-649-3909, Fax: 414-649-3551,

Email: publishing5@aurora.org

\section{Introduction}

Coronary artery bypass graft (CABG) surgery is the standard treatment for left main coronary artery (LMCA) stenosis, based primarily on studies showing significant survival benefit of CABG compared with medical therapy. ${ }^{1,2}$ According to the 2005 American College of Cardiology/American Heart Association/Society for Cardiac Angiography and Interventions guidelines, percutaneous coronary intervention (PCI) of unprotected LMCA is considered a class IIa indication for patients ineligible for $\mathrm{CABG}$ and a class III indication for patients eligible for CABG. ${ }^{3}$ In the 2009 updated guidelines, LMCA stenting was designated class $\mathrm{IIb}$ in patients with anatomic conditions associated with a low risk of PCI procedural complications and clinical conditions that predict an increased risk of adverse surgical outcomes. ${ }^{4}$

Use of bare-metal stents for LMCA disease has been associated with high 1- to 2-year mortality rates, averaging 17\% (range: 3-31\%), and repeat revascularization rates, averaging $29 \%$ (range: $15-34 \%$ ). ${ }^{5}$ The introduction of drugeluting stents (DES) has revolutionized PCI, improving clinical outcomes over bare-metal stenting and reducing the need for target lesion revascularization due to restenosis. Results of studies on the use of DES in the treatment of unprotected LMCA stenosis are encouraging..$^{6-9}$

We evaluated safety and clinical outcome of elective unprotected LMCA stenting in patients deemed to be nonsurgical candidates at our institution.

\section{Methods}

\section{Population}

We retrospectively identified all consecutive adult patients who underwent elective, unprotected LMCA stenting at our institution between October 2004 and June 2006. We excluded patients who underwent emergent LMCA stenting or protected LMCA stenting. The study was fully supported by the hospital administration and approved by the institutional review board. 


\section{Procedures}

Indications for LMCA stenting included unstable angina, non-ST-segment elevation myocardial infarction (NSTEMI), or evidence of myocardial ischemia on stress testing. Patients were risk-stratified for CABG according to the European System for Cardiac Operative Risk Evaluation (euroSCORE). Both standard and logistic euroSCORES were calculated for each patient, since the standard euroSCORE may underestimate the risk in very high-risk patients.

All procedures were performed according to concurrent guidelines. Choice of stent (drug-eluting or bare-metal), stenting technique, debulking before stenting, intravascular ultrasound guidance, prophylactic intraaortic balloon pump use, and anticoagulation/antiplatelet regimen (bivalirudin, glycoprotein IIb/IIIa inhibitors, and/or heparin/enoxaparin) was at the discretion of the treating interventional cardiologist. Appropriate informed consent for the procedure was obtained from all patients.

Unless otherwise contraindicated, all patients received clopidogrel (75 or $300 \mathrm{mg}$ loading dose) and aspirin (325 mg) prior to intervention. After the procedure and in the absence of contraindications, patients were prescribed aspirin (325 mg daily initially, followed by 81 to $325 \mathrm{mg}$ for life) and clopidogrel bisulphate (75 mg daily for at least 12 months and continued long term if well tolerated and no contraindication). All patients were monitored for at least 24 hours in the coronary intensive care unit. All patients received follow-up, with the first visit within 4-6 weeks of procedure.

Indications for repeat angiography were acute coronary syndrome, stable angina with evidence of ischemia on stress testing, or routine follow-up angiogram. Repeat revascularization was done when needed.

\section{Definitions}

Procedural success rate was defined as residual stenosis of less than $20 \%$ and establishment of Thrombolysis in Myocardial Infarction (TIMI)-3 flow without major periprocedural adverse event (death, myocardial infarction, emergency revascularization). NSTEMI was defined as elevation of cardiac markers (troponin-I and creatine kinase-MB) above the upper limits of normal, per our laboratory standard, without ST-segment elevation on electrocardiogram. ST-segment elevation myocardial infarction (STEMI) was defined as at least $1 \mathrm{~mm}$ of ST-segment elevation in at least two contiguous leads and reciprocal changes with or without elevated cardiac markers. Unstable angina was defined as new-onset angina, rest angina, angina of increasing frequency or intensity, or angina lasting longer than 20 minutes. Major adverse cardiac and cerebrovascularevent(MACCE) was defined as cardiac death, myocardial infarction, target vessel revascularization (TVR) and cerebrovascular accident. TVR was defined as repeat revascularization (PCI or CABG) caused by LMCA stenosis.

\section{Endpoints}

The primary endpoint was MACCE at 30 days, at 16 months and at 96 months. Secondary endpoints were improvement in left ventricular ejection fraction (LVEF) and rate of major periprocedural complications.

\section{Statistical Analysis}

Continuous variables were presented as medians with interquartile ranges (IQR). Categorical variables were presented as counts and percentages. Baseline and follow-up LVEF were compared using Wilcoxon signed-rank test. Association between certain variables and MACCE incidence was evaluated using chi-square or Fisher's exact tests. A two-tailed value of $\mathrm{P}<0.05$ was considered statistically significant. All statistical analysis was performed using SAS Version 9.2 (SAS Institute Inc., Cary, NC).

\section{Results}

\section{Baseline Patient Characteristics}

Between October 2004 and June 2006, 50 consecutive patients underwent elective, unprotected LMCA stenting at our institution. Baseline characteristics are presented in Table 1. Median age was 74.3 years. There were more males $(60 \%)$ than females. All patients were at high surgical risk with median logistic and standard euroSCORES of 28.6 and 12 , respectively. There was a prevalence of history of coronary artery disease with prior myocardial infarction in $60 \%, \mathrm{CABG}$ in $44 \%$ and $\mathrm{PCI}$ in $40 \%$ of patients. The most prevalent risk factor for coronary artery disease was hypertension (84\%), followed by dyslipidemia (76\%), peripheral artery disease (52\%), smoking (46\%), diabetes mellitus (44\%) and renal failure (40\%). Median LVEF was 50\%, with most values falling between $35 \%$ and $55 \%$. Prior congestive heart failure was present in $40 \%$ of patients. All patients received dual antiplatelet therapy. A high percentage of patients received statins (90\%), beta blockers (84\%) and angiotensin-converting enzyme inhibitors or angiotensin receptor blockers (70\%).

\section{Lesion and Procedural Data}

Lesion and procedural characteristics are presented in Table 2. Median LMCA stenosis was $80 \%$. The majority of lesions were de novo lesions (96\%). About two-thirds of the LMCA lesions were at the distal bifurcation (68\%), consistent with reported data in the literature. The ostial and proximal LMCA was involved in $24 \%$ of patients, while the mid-LMCA was involved 
Table 1. Baseline patient characteristics

\begin{tabular}{lc}
\hline Characteristic & $\mathrm{n}=\mathbf{5 0}(\mathbf{1 0 0 \% )}$ \\
\hline Demographics & \\
Median age, years (IQR) & $74.3(64.5-81.7)$ \\
Female & $20(40 \%)$ \\
Median logistic euroSCORE (IQR) & $28.6(14.6-43.4)$ \\
Median standard euroSCORE (IQR) & $12(9-14)$ \\
Medical history & \\
Median left ventricular ejection fraction (IQR) & $50 \%(35-55)$ \\
Cardiogenic shock & $2(4 \%)$ \\
Prior myocardial infarction & $30(60 \%)$ \\
Prior percutaneous coronary intervention & $20(40 \%)$ \\
Coronary artery bypass graft & $22(44 \%)$ \\
Valve replacement & $1(2 \%)$ \\
Atrial fibrillation & $9(18 \%)$ \\
Congestive heart failure & $21(42 \%)$ \\
Implantable cardioverter-defibrillator & $2(4 \%)$ \\
Permanent pacemaker & $5(10 \%)$ \\
Renal failure & $20(40 \%)$ \\
Dyslipidemia & $38(76 \%)$ \\
Diabetes mellitus & $22(44 \%)$ \\
Cigarette smoker & $23(46 \%)$ \\
Chronic lung disease & $16(32 \%)$ \\
Peripheral artery disease & $26(52 \%)$ \\
Cerebrovascular accident & $8(16 \%)$ \\
Hypertension & $42(84 \%)$ \\
Medications & \\
Aspirin & $50(100 \%)$ \\
Clopidogrel & $50(100 \%)$ \\
Beta blocker & $42(84 \%)$ \\
Calcium channel blocker & $10(20 \%)$ \\
ACEl/ARB & $35(70 \%)$ \\
Nitrates & $30(60 \%)$ \\
Statin drugs & $45(90 \%)$ \\
\hline
\end{tabular}

$A C E I$, angiotensin-converting enzyme inhibitor; $A R B$, angiotensin receptor blocker; IQR, interquartile range.

in $8 \%$. More patients received bivalirudin (54\%) alone than a combination of heparin and IIb/IIIa inhibitors (46\%).

A total of 67 stents were deployed, predominantly DES (94\%). Two stents were deployed in the LMCA in $66 \%$ of patients, whereas a single stent was deployed in $17 \%$. Kissing technique was used in $24 \%$ and crush technique in $10 \%$. Debulking prior to stent deployment was used in $6 \%$ of patients. Prophylactic intraaortic balloon pump was used in $6 \%$. Postintervention TIMI-3 flow and residual stenosis less than $20 \%$ were achieved in all patients. Procedural success rate was $100 \%$ (Table 3).

\section{Primary Endpoint}

Clinical outcomes recorded at two median follow-up periods (16 and 96 months) are presented in Table 4. At 30 days, incidence of myocardial infarction, cerebrovascular accident, TVR and cardiac death was $4 \%, 2 \%, 4 \%$ and $2 \%$, respectively.
Table 2. Lesion and procedural characteristics

\begin{tabular}{lc}
\hline Characteristic & $\mathbf{n = 5 0 ( 1 0 0 \% )}$ \\
\hline Severity of stenosis & \\
LMCA stenosis (IQR) & $80(70-85)$ \\
RCA stenosis (IQR) & $80(40-100)$ \\
LAD stenosis (IQR) & $80(65-95)$ \\
CIRC stenosis (IQR) & $80(60-90)$ \\
Prior LMCA stent & \\
De novo & $48(96 \%)$ \\
In-stent & $2(4 \%)$ \\
Stent type & \\
Drug-eluting & $63(94 \%)$ \\
Bare-metal & $4(6 \%)$ \\
Lesion location & \\
Ostial/proximal & $12(24 \%)$ \\
Mid-segment & $4(8 \%)$ \\
Distal & $34(68 \%)$ \\
Number of stents within LMCA & \\
One & $33(66 \%)$ \\
Two & $17(34 \%)$ \\
Number of vessels stented & \\
One & $23(46 \%)$ \\
Two & $23(46 \%)$ \\
Three & $27(54 \%)$ \\
Four & $5(10 \%)$ \\
Kissing & $3(24 \%)$ \\
Crush & $3(66 \%)$ \\
Single & $3(6 \%)$ \\
Rotational atherectomy & \\
IABP use & \\
Medications & \\
Heparin & \\
Glycoprotein IIb/IIla inhibitors & \\
Angiomax & \\
\hline
\end{tabular}

CIRC, circumflex artery; IABP, intra-aortic balloon pump; IQR, interquartile range; $L A D$, left anterior descending artery; $L M C A$, left main coronary artery; $R C A$, right coronary artery.

Of the two patients who had myocardial infarction, one had STEMI and was treated with CABG and the other had NSTEMI and was treated with repeat PCI. At 16 months, incidence of myocardial infarction, cerebrovascular accident, TVR and cardiac death was $6 \%, 2 \%, 6 \%$ and $2 \%$, respectively. Beyond 30 days and up to 16 months, there was one NSTEMI and one repeat PCI. At 96 months, incidence of myocardial infarction, cerebrovascular accident, TVR and cardiac death was $6 \%, 2 \%, 12 \%$ and $4 \%$, respectively. MACCE rate was $12 \%$ at 30 days, $16 \%$ at 16 months and $24 \%$ at 96 months.

\section{Secondary Endpoints}

Periprocedural complications are presented in Table 3. Evaluation for major complications included: emergent CABG, 
Table 3. Procedural outcomes

\begin{tabular}{lc}
\hline Variable & $\mathbf{n = 5 0}(\mathbf{1 0 0} \%)$ \\
\hline Procedural success & \\
Residual stenosis & $46(92 \%)$ \\
$0 \%$ & $4(8 \%)$ \\
Less than 20\% & 0 \\
More than 20\% & $50(100 \%)$ \\
Post-PCI TIMl-3 flow & $50(100 \%)$ \\
Procedural success & \\
Periprocedural complications & 0 \\
Postprocedure cardiogenic shock & 0 \\
Vascular perforation & 0 \\
LMCA dissection & 0 \\
Abrupt closure & 0 \\
Tamponade & 0 \\
Aortic dissection & 0 \\
Emergent CABG & 0 \\
Death & 0 \\
Other complication & \\
\hline
\end{tabular}

CABG, coronary artery bypass graft; LMCA, left main coronary artery; $\mathrm{PCl}$, percutaneous coronary intervention; TIMI, Thrombolysis in Myocardial Infarction.

LMCA dissection, abrupt vessel closure, vascular perforation, cardiac tamponade, procedure-related cardiogenic shock and procedure-related death. There were no major periprocedural complications. Median baseline LVEF was 50\% (IQR: 35-55\%). Median follow-up LVEF was 55\% (IQR: 45-60\%). Two-tailed Wilcoxon signed-rank test showed significant overall improvement $(+5 \%)$ in LVEF $(\mathrm{P}<0.001)$ (Table 4).

\section{Predictors for MACCE}

Certain clinical variables, including age, gender, history of myocardial infarction, PCI, diabetes mellitus, renal failure and baseline LVEF, were tested for possible association with MACCE at 16 months (Table 5). No association, except baseline renal failure ( $\mathrm{P}=0.047$ ), was documented. Lesion location, stent type, stenting technique, number of stents, and number of vessels stented also were tested for their possible association with MACCE at 16 months. No significant associations were found.

\section{Discussion}

Use of PCI for LMCA stenosis has been an area of great debate, and $\mathrm{CABG}$ remains the standard of care. Initial attempts at percutaneous transluminal coronary angioplasty in LMCA were discouraging. ${ }^{10,11}$ Our study shows unprotected LMCA stenting is feasible and safe in high-risk patients. Our procedure success rate was $100 \%$, and there were no major procedure-related complications.

This single-center study is a reflection of "real-world" outcomes. All patients were at very high surgical risk, with
Table 4. Clinical outcomes at short-, intermediate- and long-term follow-up

\begin{tabular}{|c|c|}
\hline Variable & $n=50(100 \%)$ \\
\hline \multicolumn{2}{|l|}{ Short-term (30-day) outcome } \\
\hline Myocardial infarction & $2(4 \%)$ \\
\hline STEMI & $1(2 \%)$ \\
\hline NSTEMI & $1(2 \%)$ \\
\hline Cerebrovascular accident & $1(2 \%)$ \\
\hline Target vessel revascularization & $2(4 \%)$ \\
\hline CABG & $1(2 \%)$ \\
\hline $\mathrm{PCl}$ & $1(2 \%)$ \\
\hline Cardiovascular death & $1(2 \%)$ \\
\hline MACCE $^{*}$ & $6(12 \%)$ \\
\hline \multicolumn{2}{|l|}{ Intermediate-term (16-month) outcome } \\
\hline Myocardial infarction & $3(6 \%)$ \\
\hline STEMI & $1(2 \%)$ \\
\hline NSTEMI & $2(4 \%)$ \\
\hline Cerebrovascular accident & $1(2 \%)$ \\
\hline Target vessel revascularization & $3(6 \%)$ \\
\hline CABG & $1(2 \%)$ \\
\hline $\mathrm{PCl}$ & $2(4 \%)$ \\
\hline Cardiovascular death & $1(2 \%)$ \\
\hline All $\mathrm{PCl}$ & $8(16 \%)$ \\
\hline MACCE $^{*}$ & $8(16 \%)$ \\
\hline Mean follow-up LVEF (IQR) & $55 \%(45-60)$ \\
\hline Mean improvement of LVEF (IQR) & $5 \%(0-10) \dagger$ \\
\hline Improved LVEF & $31(62 \%)$ \\
\hline Same LVEF & $13(25 \%)$ \\
\hline Worsened LVEF & $6(12 \%)$ \\
\hline \multicolumn{2}{|l|}{ Long-term (96-month) outcome } \\
\hline Myocardial infarction & $3(6 \%)$ \\
\hline STEMI & $1(2 \%)$ \\
\hline NSTEMI & $2(4 \%)$ \\
\hline Cerebrovascular accident & $1(2 \%)$ \\
\hline Target vessel revascularization & $6(12 \%)$ \\
\hline CABG & $2(4 \%)$ \\
\hline $\mathrm{PCl}$ & $4(8 \%)$ \\
\hline Cardiovascular death & $2(4 \%)$ \\
\hline All $\mathrm{PCl}$ & $20(40 \%)$ \\
\hline MACCE* & $12(24 \%)$ \\
\hline
\end{tabular}

*MACCE includes cerebrovascular accident, myocardial infarction, target vessel revascularization and death from cardiovascular disease.

TLVEF was significantly improved compared with baseline LVEF $(P<0.001$, two-tailed Wilcoxon signed-rank test).

$C A B G$, coronary artery bypass graft; IQR, interquartile range; $L V E F$, left ventricular ejection fraction; MACCE, major adverse cardiac and cerebrovascular event; PCI, percutaneous coronary intervention; STEMI, ST-segment elevation myocardial infarction; NSTEMI, non-ST-segment elevation myocardial infarction.

median estimated perioperative mortality of $28.6 \%$ (IQR: 14.4-43.4\%). These patients were appropriately declined by surgeons and treated with LMCA stenting in accordance with concurrent guidelines. Although all patients were high risk, and $68 \%$ of them had lesions located in the distal bifurcation segment (the most problematic lesion 


\begin{tabular}{|c|c|c|c|c|}
\hline Characteristic & $\begin{array}{c}\text { Overall } \\
n=50\end{array}$ & $\begin{array}{c}\text { No MACCE } \\
n=42\end{array}$ & $\begin{array}{c}\text { MACCE } \\
n=8\end{array}$ & P-value* \\
\hline \multicolumn{5}{|l|}{ Demographics } \\
\hline Median age, years (IQR) & $74.3(64.5-81.7)$ & $74.9(65.8-81.8)$ & 71.7 (60.4-76.7) & 0.478 \\
\hline Female & $20(40 \%)$ & $16(38.1 \%)$ & $4(50.0 \%)$ & 0.697 \\
\hline Myocardial infarction & $30(60 \%)$ & $24(57.1 \%)$ & $6(75.0 \%)$ & 0.345 \\
\hline $\mathrm{PCl}$ & $20(40 \%)$ & $17(40.5 \%)$ & $3(37.5 \%)$ & 1.000 \\
\hline Diabetes mellitus & $22(44 \%)$ & $17(40.5 \%)$ & $5(62.5 \%)$ & 0.277 \\
\hline Renal failure & $20(40 \%)$ & $14(33.3 \%)$ & $6(75.0 \%)$ & 0.047 \\
\hline CABG & $22(44 \%)$ & $19(45.2 \%)$ & $3(37.5 \%)$ & 1.000 \\
\hline Median LVEF (IQR) & $50 \%(35-55)$ & $50 \%(35-55)$ & $53 \%(24-58)$ & 0.748 \\
\hline \multicolumn{5}{|l|}{ Prior LMCA stent } \\
\hline De novo & $48(96 \%)$ & $40(95.2 \%)$ & $8(100 \%)$ & 1.000 \\
\hline In-stent & $2(4 \%)$ & $2(4.8 \%)$ & $0(0 \%)$ & \\
\hline \multicolumn{5}{|l|}{ Stent type } \\
\hline Drug-eluting & $46(92 \%)$ & $38(90.5 \%)$ & $8(100 \%)$ & 0.842 \\
\hline Bare-metal & $4(8 \%)$ & $4(9.5 \%)$ & $0(0 \%)$ & 1.000 \\
\hline \multicolumn{5}{|l|}{ Lesion locations } \\
\hline Ostial & $11(22 \%)$ & $9(21.4 \%)$ & $2(25.0 \%)$ & 1.000 \\
\hline Proximal & $1(2 \%)$ & $1(2.4 \%)$ & $0(0 \%)$ & 1.000 \\
\hline Mid & $4(8 \%)$ & $3(7.1 \%)$ & $1(12.5 \%)$ & 0.514 \\
\hline Distal & $34(68 \%)$ & $29(69.1 \%)$ & $5(62.5 \%)$ & 0.699 \\
\hline \multicolumn{5}{|l|}{ No. of stents within LMCA } \\
\hline One & $33(66 \%)$ & $27(64.3 \%)$ & $6(75.0 \%)$ & 0.699 \\
\hline Two & $17(34 \%)$ & $15(35.7 \%)$ & $2(25.0 \%)$ & \\
\hline \multicolumn{5}{|l|}{ No. of vessels stented } \\
\hline One & $5(10 \%)$ & $4(9.5 \%)$ & $1(12.5 \%)$ & 1.000 \\
\hline Two & $25(50 \%)$ & $22(52.4 \%)$ & $3(37.5 \%)$ & 0.702 \\
\hline Three & $19(38 \%)$ & $15(35.7 \%)$ & $4(50 \%)$ & 0.459 \\
\hline Four & $1(2 \%)$ & $1(2.4 \%)$ & $0(0 \%)$ & 1.000 \\
\hline \multicolumn{5}{|l|}{ Stent technique } \\
\hline Kissing & $12(24 \%)$ & $10(23.8 \%)$ & $2(25.0 \%)$ & 1.000 \\
\hline Crush & $6(12 \%)$ & $6(14.3 \%)$ & $0(0 \%)$ & 0.572 \\
\hline Single & $32(64 \%)$ & $26(61.9 \%)$ & $6(75 \%)$ & 0.760 \\
\hline
\end{tabular}

*P-values were calculated by chi-squared tests or Fisher's exact tests (two-tailed).

$C A B G$, coronary artery bypass graft; IQR, interquartile range; LMCA, left main coronary artery; LVEF, left ventricular ejection fraction; MACCE, major adverse cardiac and cerebrovascular event; $P C I$, percutaneous coronary intervention.

presentation), MACCE rates at 30 days (12\%), 16 months (16\%) and 96 months (24\%) were within an acceptable range. Cardiovascular mortality $(2 \%$ at 30 days, $2 \%$ at 16 months, $4 \%$ at 96 months) and TVR (4\% at 30 days, $6 \%$ at 16 months, $12 \%$ at 96 months) were similar or lower than the rates reported in the studies later discussed. It must be noted that the majority of patients received DES.

A review of eight studies on LMCA stenting using bare-metal stents reported increased 1- to 2-year mortality (17\%) and repeat revascularization rates $(29 \%) .{ }^{4}$ The Unprotected Left Main Trunk Intervention Multicenter Assessment (ULTIMA) registry demonstrated a high 1-year cardiac mortality rate of $20.2 \%$ in high-risk patients and patients with low LVEF. ${ }^{12}$ In our study, 4 patients were stented with bare-metal stents; none experienced MACCE complications. The availability of larger diameters in the newer DES may resolve the issue of having to choose bare-metal stents over DES due to vessel size.

The advent of DES renewed the hope for a percutaneous alternative to surgery in the treatment of LMCA disease. Erglis et al. reported better major adverse cardiac event (MACE)-free survival rates with paclitaxel-eluting stents compared to bare-metal stents $(87 \%$ vs. $70 \%) .{ }^{13}$ Similarly, Park et al. reported better 1-year freedom from death, myocardial infarction and TVR with sirolimus-eluting stents compared to bare-metal stents $(98.0 \%$ vs. $81.4 \%) .{ }^{8}$ More recently, Kubo and colleagues demonstrated the incidence of target lesion revascularization at 7 years was significantly lower in DES compared to bare-metal stents (26.4\% vs. 
$40.5 \%, \mathrm{P}=0.009$ ), although incidence rates at $1-4$ years and beyond 4 years were similar. In addition, the incidence of cardiac death or nonfatal myocardial infarction was similar between the two groups. ${ }^{14}$ The Drug-Eluting Stent for Left Main (DELFT) Registry followed patients with emergent and elective unprotected LMCA stenting with DES for up to 3 years. Incidence of cardiac death at 30 days, 1 year and 3 years was $3.3 \%, 6.7 \%$ and $9.2 \%$, respectively. Incidence of TVR was $0.8 \%, 10 \%$ and $14.2 \%$, respectively. MACE rate was $11.4 \%, 24.3 \%$ and $32.1 \%$. MACE was significantly higher with emergent PCI at 30 days and 1 year, while cardiac death was significantly higher with emergent PCI at 3 years. ${ }^{15}$ These studies demonstrate favorable short- and long-term outcomes with elective unprotected LMCA stenting.

There is a paucity of large randomized trials directly comparing DES and CABG for unprotected LMCA. This might be, in part, due to $\mathrm{CABG}$ being considered the standard of care treatment for significant LMCA stenosis and the feared consequences of stent thrombosis in LMCA. Early reports documented mortality rates of $1.7-7.0 \%$ following CABG for LMCA stenosis, and 1-year mortality rates of $6-14 \%$ are reported in more contemporary retrospective studies. ${ }^{16-18}$ The Revascularization for Unprotected Left Main Coronary Artery Stenosis: Comparison of Percutaneous Coronary Angioplasty Versus Surgical Revascularization (MAINCOMPARE) registry compared unprotected LMCA stenting ( $71 \%$ DES) with CABG in 2,240 nonrandomized patients. This study showed a significantly lower rate of freedom from repeat revascularization with DES at 3 years than with CABG $(90.7 \%$ vs. $98.4 \%, \mathrm{P}=0.001)$. Threeyear all-cause mortality was not different $(6.1 \%$ in PCI group, $8.3 \%$ in $\mathrm{CABG}$ group). There were no significant differences in rate of death or the composite endpoint of death, Q-wave myocardial infarction, or stroke between patients receiving stents and those undergoing CABG. ${ }^{19,20}$ In our study, rate of cardiac death was $2 \%$ at 30 days, $2 \%$ at 16 months and $4 \%$ at 96 months, lower or similar to CABG rates. The Study of Unprotected Left Main Stenting Versus Bypass Surgery (LE MANS) was a small randomized trial that compared unprotected LMCA stenting with CABG in relatively low-risk patients with normal LVEF. Thirtyday MACCE was lower with PCI. One-year MACCE-free survival was similar in the two groups. A trend towards improved survival was seen with PCI. LVEF improved in the PCI group. ${ }^{21}$ In the randomized Synergy Between Percutaneous Coronary Intervention With TAXUS and Cardiac Surgery (SYNTAX) trial that compared CABG with PCI for left main/multivessel disease, there were 705 patients with LMCA disease (CABG: 348 patients,
PCI: 357 patients). For this group of patients, the overall safety endpoint of death, myocardial infarction and cerebrovascular accident was similar $(\mathrm{P}=0.29)$ for $\mathrm{CABG}$ (9.1\%) and PCI (7.0\%). Overall MACCE also was similar (CABG: $13.6 \%$, PCI: $15.8 \%, \mathrm{P}=0.44$ ). PCI was associated with better MACCE rates compared with $\mathrm{CABG}$ in the subset of patients with isolated LMCA disease $(7.1 \%$ vs. $8.5 \%$ ) or LMCA with 1-vessel coronary artery disease (7.5\% vs. $13.2 \%) .^{22}$ Park et al. followed 350 patients with unprotected LMCA disease who underwent PCI (with bare-metal stents) or CABG over a 10-year period and 395 patients with unprotected LMCA disease who underwent PCI with DES or CABG over a 5 -year period. ${ }^{23}$ In the 10-year follow-up cohort of bare-metal stents and concurrent CABG, the adjusted risks of death (hazard ratio [HR]: 0.81; $95 \%$ confidence interval $[\mathrm{CI}]: 0.44-1.50 ; \mathrm{P}=0.50)$ and the composite of death, Q-wave myocardial infarction, or stroke (HR: $0.92 ; 95 \%$ CI: $0.55-1.53 ; \mathrm{P}=0.74$ ) were similar between the two groups. The rate of TVR was significantly higher in the group that received bare-metal stents (HR: 10.34; 95\% CI: 4.61-23.18; $\mathrm{P}<0.001) .{ }^{23}$ In the 5-year follow-up cohort of DES and concurrent CABG, there was no significant difference in the adjusted risk of death (HR: 0.83; 95\% CI: $0.34-2.07 ; \mathrm{P}=0.70)$ or the risk of the composite outcome (HR: $0.91 ; 95 \% \mathrm{CI}: 0.45-1.83 ; \mathrm{P}=0.79$ ). The rates of TVR also were higher in the DES group than the CABG group (HR: 6.22; 95\% CI: 2.26-17.14; $\mathrm{P}<0.001$ ). ${ }^{23}$ These results are encouraging for use of DES in the treatment of unprotected LMCA. The MACCE and cardiac mortality rates reported in our study are consistent with these results.

Our study showed significant improvement in LVEF postPCI. Significant improvement in LVEF post-PCI compared with CABG was reported in the LE MANS study. This differential improvement in LVEF was explained, in part, by restoration of physiologic anterograde flow in the LMCA and major vessels, lack of perioperative reperfusion injury and low incidence of myocardial infarction. ${ }^{21}$

Some authors reported predictors for adverse events following unprotected LMCA stenting. These included age, high euroSCORE, reduced LVEF, insulin-dependent diabetes mellitus and multiple stenting. ${ }^{15,24}$ In our study, no association was found between MACCE and age, gender, history of myocardial infarction, PCI, diabetes, baseline LVEF or euroSCORE. However, there was an association between baseline renal failure and $\mathrm{MACCE}(\mathrm{P}=0.047)$. Lesion location, stent type, stenting technique, number of stents and number of vessels stented did not predict MACCE. Ability to see differences may have been hindered by the low MACCE rate. 


\section{Study Limitations}

There are some limitations to this study. The study population size is small; use of unprotected LMCA stenting is limited by current guidelines to patients ineligible for surgery. No direct comparison with $\mathrm{CABG}$ was done. Intravascular ultrasound and routine angiographic follow-up was not done in all patients. Given the high surgical risk in our patients, the results of this study may not be extrapolated to patients at lower surgical risk.

\section{Conclusion}

In nonsurgical patients with left main disease, stenting of unprotected left main coronary artery is safe, with acceptable rates of MACCE seen up to 96 months poststenting.

\section{Acknowledgments}

The authors gratefully acknowledge Barbara Danek and Katie Klein for the editorial preparation of the manuscript.

\section{Conflicts of Interest}

None.

\section{References}

1. Yusuf S, Zucker D, Peduzzi P, et al. Effect of coronary artery bypass graft surgery on survival: overview of 10-year results from randomized trials by the Coronary Artery Bypass Graft Surgery Trialists Collaboration. Lancet. 1994;344:563-70.

2. Caracciolo EA, Davis KB, Sopko G, et al. Comparison of surgical and medical group survival in patients with left main equivalent coronary artery disease. Long-term CASS experience. Circulation. 1995;91:2335-44.

3. Smith SC Jr, Feldman TE, Hirshfeld JW Jr, et al. ACC/AHA/SCAI 2005 Guideline Update for Percutaneous Coronary InterventionSummary Article: a report of the American College of Cardiology/ American Heart Association Task Force on Practice Guidelines (ACC/AHA/SCAI Writing Committee to Update the 2001 Guidelines for Percutaneous Coronary Intervention). $\mathrm{J} \mathrm{Am}$ Coll Cardiol. 2006;47:216-35.

4. Kushner FG, Hand M, Smith SC Jr, et al. 2009 focused updates: ACC/ AHA guidelines for the management of patients with ST-elevation myocardial infarction (updating the 2004 guideline and 2007 focused update) and ACC/AHA/SCAI guidelines on percutaneous coronary intervention (updating the 2005 guideline and 2007 focused update) a report of the American College of Cardiology Foundation/American Heart Association Task Force on Practice Guidelines. J Am Coll Cardiol. 2009;54:2205-41.

5. Taggart DP, Boden WE, Guyton RA, Shemin RJ, Yusuf S. Revascularization for unprotected left main coronary artery stenosis. Stenting or surgery. J Am Coll Cardiol. 2008;51:885-92.

6. Chieffo A, Colombo A. Treatment of unprotected left main coronary artery disease with drug-eluting stents: is it time for a randomized trial? Nat Clin Pract Cardiovasc Med. 2005;2:396-400.

7. Chieffo A, Stankovic G, Bonizzoni E, et al. Early and mid-term results of drug-eluting stent implantation in unprotected left main. Circulation. 2005;111:791-5.

8. Park SJ, Kim YH, Lee BK, et al. Sirolimus-eluting stent implantation for unprotected left main coronary artery stenosis: comparison with bare metal stent implantation. J Am Coll Cardiol. 2005;45:351-6.
9. Valgimigli M, van Mieghem CA, Ong AT, et al. Short- and longterm clinical outcome after drug-eluting stent implantation for the percutaneous treatment of left main coronary artery disease: insights from the Rapamycin-Eluting and Taxus Stent Evaluated At Rotterdam Cardiology Hospital registries (RESEARCH and T-SEARCH). Circulation. 2005;111:1383-9.

10. O'Keefe JH, Hartzler GO, Rutherford BD, et al. Left main coronary angioplasty: early and late results of 127 acute and elective procedures. Am J Cardiol. 1989;64:144-7.

11. Hartzler GO, Rutherford BD, McConohay DR, Johnson WL, Giorgi LV. "High-risk" percutaneous transluminal coronary angioplasty. Am J Cardiol. 1988;61:33G-37G.

12. Tan WA, Tamai H, Park SJ, et al. Long term clinical outcomes after unprotected left main trunk percutaneous revascularization in 279 patients. Circulation. 2001;104:1609-14.

13. Erglis A, Narbute I, Indulis Kumsars I, et al. A randomized comparison of paclitaxel-eluting stents versus bare metal stents for treatment of unprotected left main coronary artery stenosis. $\mathrm{J} \mathrm{Am} \mathrm{Coll} \mathrm{Cardiol.}$ 2007;50:491-7.

14. Kubo S, Kadota K, Shimada T, et al. Seven-year clinical outcomes of unprotected left main coronary artery stenting with drug-eluting stent and bare-metal stent. Circ J. 2013;77:2497-504.

15. Meliga E, Garcia-Garcia HM, Valgimigli M, et al. Longest available clinical outcomes after drug-eluting stent implantation for unprotected left main coronary artery disease. The DELFT (Drug Eluting stent for LeFT main) Registry. J Am Coll Cardiol. 2008;51:2212-9.

16. Beauford RB, Saunders CR, Lunceford TA, et al. Multivessel offpump revascularization in patients with significant left main coronary artery stenosis: early and midterm outcome analysis. J Card Surg. 2005;20:112-8.

17. d'Allonnes FR, Corbineau H, Le Breton H, Leclercq C, Leguerrier A, Daubert C. Isolated left main coronary artery stenosis: long term follow up in 106 patients after surgery. Heart. 2002;87:544-8.

18. Holm F, Lubanda JC, Semrad M, et al. Main clinical and surgical determinants of in-hospital mortality after surgical revascularization of left main coronary artery stenosis: 2 year retrospective study (1998-1999). J Mal Vasc. 2004;29:89-93.

19. Jones RH. Percutaneous intervention vs. coronary-artery bypass grafting in left main coronary disease. $N$ Engl J Med. 2008;358:1851-3.

20. Seung KB, Park DW, Kim YH, et al. Stents versus coronary-artery bypass grafting for left main coronary artery disease. $N$ Engl J Med. 2008;358:1781-92.

21. Buszman PE, Kiesz SR, Bochenek A, et al. Acute and late outcomes of unprotected left main stenting in comparison with surgical revascularization. (Study of Unprotected Left Main Stenting Versus Bypass Surgery [LE MANS study]). J Am Coll Cardiol. 2008;51:538-45.

22. Serruys PW, Morice MC, Kappetein AP, et al. Percutaneous coronary intervention versus coronary-artery bypass grafting for severe coronary artery disease. $N$ Engl J Med. 2009;360:961-72.

23. Park DW, Kim YH, Yun SC, et al. Long-term outcomes after stenting versus coronary artery bypass grafting for unprotected left main coronary artery disease: 10-year results of bare-metal stents and 5 -year results of drug-eluting stents from the ASAN-MAIN (ASAN Medical Center-Left MAIN Revascularization) Registry. J Am Coll Cardiol. 2010;56:1366-75.

24. Buszman PE, Buszman PP, Kiesz RS, et al. Early and long-term results of unprotected left main coronary artery stenting. The LE MANS (Left Main Coronary Artery Stenting) Registry. J Am Coll Cardiol. 2009;54:1500-11.

(C) 2014 Aurora Health Care, Inc. 